\title{
Perspektif Potensi Lokal Sancang: Sebuah Refleksi untuk Meningkatkan Pemahaman Etnopedagogik
}

\author{
Diana Hernawati $^{1}$, Liah Badriah ${ }^{2}$, Romy Faisal Mustofa ${ }^{3}$ \\ 1,2,3 Jurusan Pendidikan Biologi Universitas Siliwangi Tasikmalaya \\ Jalan Siliwangi No. 24 Kota Tasikmalaya 46115 \\ Email: hernawatibiologi@unsil.ac.id \\ DOI : $10.32672 / \mathrm{btm} . v 1 \mathrm{i} 4.1721$
}

\begin{abstract}
Sancang forest has quite a variety of potential located in the South Garut area, holding many mystery legends that affect the attitude of life in the surrounding community. Some of the potential possessed include flora, fauna, and landscape that are still sustainable with the availability of water and air. In some forest locations, there is forest destruction that is generally done by persons outside the Sancang community. The efforts offered through this counseling include understanding the existence of elements of local culture, so that they do not perish along with the times and the current of modernization; how the natural environment affects the culture of a society; and how ethnopedagogic role is in preserving the balance of the ecosystem and making use of local culture. The Sancang community it self still holds the customary law "pikukuh" which has been passed down from generation to generation very strongly, so it is unyielding for indigenous people to break the law. This customary law indirectly makes the community have values and culture that tend to protect nature and the environment. This dedication activity was carried out to further foster public awareness of the existence of the Sancang forest in relation to the legend of the Sundanese ancestors who were still strongly held and had given birth to local wisdom of the local community in addressing and preserving the natural surroundings. With the concept of ethnopedagogic, it is hoped that it can improve the understanding of culture-based communities to protect the forest as a part of supporting people's lives. Ethnopedagogics views local knowledge or wisdom as a source of innovation and skills that can be empowered for the welfare of society. The object in this activity is the community around the Leuweung Sancang Nature Reserve (CA) as many as 40 people consisting of indigenous people, school students, and nature lovers groups. The contribution that can be given is to provide an understanding of the management and maintenance of local culture as a potential area that must be maintained, instilling knowledge about the role of ethnopedagogics in preserving the balance of the ecosystem and making use of local culture.
\end{abstract}

Keywords: ethnopedagogic, local potential, Sancang 
BAKTIMAS

Jurnal Pengabdian pada Masyarakat
Vol. 1, No. 4,

Desember 2019
eISSN 2685-113x

pISSN 2685-0303

\begin{abstract}
ABSTRAK
Hutan Sancang memiliki potensi yang cukup beragam terletak di daerah Garut Selatan, menyimpan banyak misteri legenda yang mempengaruhi sikap hidup masyarakat di sekitarnya. Beberapa potensi yang dimiliki diantaranya adalah flora, fauna serta bentang alam yang masih lestari dengan ketersediaan air dan udaranya. Di beberapa lokasi hutan, terdapat kerusakan hutan yang umumnya dilakukan oleh oknum orang di luar masyarakat Sancang. Upaya yang ditawarkan melalui penyuluhan ini meliputi pemahaman keberadaan unsur-unsur kebudayaan lokal, supaya tidak musnah seiring dengan perkembangan zaman dan arus modernisasi; bagaimana lingkungan alam mempengaruhi kebudayaan suatu masyarakat; dan bagaimana peranan etnopedagogik dalam melestarikan keseimbangan ekosistem dan mendayagunakan kebudayaan lokal. Masyarakat Sancang sendiri masih memegang hukum adat " pikukuh" yang diwariskan turun temurun dengan sangat kuat, sehingga pantang bagi masyarakat asli untuk melanggar hukum tersebut. Hukum adat ini secara tidak langsung menjadikan masyarakat memiliki tata nilai dan budaya yang cenderung untuk menjaga alam dan lingkungannya. Kegiatan pengabdian ini dilaksanakan untuk lebih menumbuhkan kesadaran masyarakat terhadap keberadaan hutan Sancang terkait dengan legenda leluhur orang Sunda yang masih dipegang kuat dan telah melahirkan kearifan lokal masyarakat setempat dalam menyikapi dan melestarikan alam sekitarnya. Dengan adanya konsep Etnopedagogik, diharapkan dapat meningkatkan pemahaman masyarakat berbasis budaya untuk menjaga hutan sebagai bagian yang menunjang kehidupan masyarakat. Etnopedagogik memandang pengetahuan atau kearifan lokal sebagai sumber inovasi dan keterampilan yang dapat diberdayakan demi kesejahteraan masyarakat. Objek dalam kegiatan ini adalah masyarakat sekitar Cagar Alam (CA) Leuweung Sancang sebanyak 40 orang terdiri dari masyarakat asli, siswa sekolah dan kelompok pecinta alam. Kontribusi yang dapat diberikan adalah memberikan pemahaman tentang pengelolaan dan pemeliharaan kebudayaan lokal sebagai potensi daerah yang harus dijaga, menanamkan pengetahuan mengenai peranan etnopedagogik dalam melestarikan keseimbangan ekosistem dan mendayagunakan kebudayaan lokal.
\end{abstract}

Kata Kunci: etnopedagogik, potensi lokal, Sancang

\title{
PENDAHULUAN
}

Hutan sebagai sandaran kehidupan, tempat bertani dan berburu satwa diakui keberadaannya. Bentangan hutan masih lestari sampai puluhan tahun, dengan ketersediaan air dan udaranya. Tidak terkecuali dengan legenda yang menjadi wujud kepercayaan sakral masyarakatnya. Dalam alam pikiran modern, legenda tidak lagi dipandang sebagai sesuatu yang sakral, melainkan sebagai sebuah hal yang irasional, tahayul, dan tidak masuk di akal. Legenda-legenda yang pada mulanya menjadi sebuah alat kontrol sosial yang telah melahirkan kearifan-kearifan dalam menyikapi lingkungan alam, kini termarginalkan. Akibatnya sikap pemuliaan terhadap alam pun tidak lagi mendapat tempat dalam sikap dan cara berfikir yang rasional. Dengan 
kondisi seperti ini, maka lingkungan alam pun tidak lagi dipandang sebagai subyek, melainkan hanya sebagai obyek untuk memenuhi kebutuhan hidup. Lingkungan alam pun dieksploitasi (Gow, 2015).

Kondisi seperti ini dapat kita temukan juga di Sancang. Bentang alam yang menarik yang terdapat di cagar alam Sancang dengan ekosistem dan berbagai jenis flora dan fauna, serta gugusan-gugusan batu menimbulkan panorama alam yang unik. Daya tarik utama ini tidak sebanding dengan kondisi masyarakatnya. Kondisi sosial ekonomi masyarakat di sekitar cagar alam leuweung Sancang relatif rendah. Warga masyarakat di sekitar cagar alam leuweung Sancang sebagian besar bekerja sebagai petani. Tingkat pendidikan mereka pun cukup rendah, dan mereka tidak memiliki keterampilan dan keahlian cukup untuk meningkatkan taraf hidupnya. Lapangan kerja masyarakat sangat terbatas dan tergantung pada alam. Kurangnya lahan pertanian yang dimiliki oleh masyarakat setempat menyebabkan terjadi penyerobotan lahan di dalam cagar alam. Beranjak dari permasalahan tersebut di atas diperlukan usaha yang dapat mengubah gaya hidup sehingga manusia lebih bijak dalam memanfaatkan alam. Jawaban untuk menyikapi permasalahan tersebut salah satunya melalui pendidikan. Tetapi pendidikan seperti apa yang layak untuk menjawab masalah tersebut. Ada praktik pendidikan dan etnodidaktik yang terbukti baik dapat menjawab masalah tersebut yaitu melalui kearifan lokal yang layak menjadi basis pendidikan dan pembudayaan. Kami menggagas konsep etnopedagogik sebagai target khusus untuk dikembangkan dan diterapkan pada kegiatan kelompok pecinta alam maupun para penggiat alam terbuka. Di sini kami akan menjadikan masyarakat lokal sebagai Parabiologis maupun Parataksonomis yang tidak memiliki pendidikan formal tetapi memiliki kemampuan dalam bidang taksonomi maupun biologi (Janzen, Hallwachs, Jimenez, \& Gámez, 1993).

Etnopedagogik adalah praktik pendidikan berbasis kearifan lokal dalam berbagai ranah seperti pengobatan, seni bela diri, lingkungan hidup, pertanian, ekonomi, pemerintahan dan lain-lain (Fahrutdinova, 2016). Makna lain dari etnopedagogik adalah aktivitas mengajar lintas budaya. Etnopedagogik memandang pengetahuan atau kearifan lokal (local knowledge, local wisdom) sebagai sumber inovasi dan keterampilan yang dapat diberdayakan demi kesejahteraan masyarakat. Kearifan lokal adalah koleksi fakta, konsep, kepercayaan dan persepsi masyarakat terkait dunia sekitar. Pernyataan tersebut memperkuat bahwa konsep etnopedagogik sangat berkaitan erat dengan kegiatan konservasi. Istilah konservasi ini merujuk pada usaha untuk menjaga, mempertahankan dan melestarikan apa yang dimiliki untuk tetap lestari (Douglas Sheil \& Lawrence, 2004).

Konsep etnopedagogik telah memberikan pengaruh pada berbagai aspek terutama berkaitan dengan praktik pendidikan multikultur (D. Sheil, 2001;Guzmán, Roders, \& Colenbrander, 2017). Pendidikan yang bersumber dari kearifan lokal memberikan inspirasi bagi para konservator untuk menerapkan konsep kearifan lokal untuk kepentingan konservasi. Konservasi diterapkan bagi masyarakat lokal yang berdomisili di wilayah konservasi. Hal ini dilakukan karena masyarakat memiliki tata nilai dan budaya yang cenderung untuk menjaga alam dan lingkungannya. Istilah ini dalam dunia Internasional disebut dengan indigenous knowledge. Dalam pelbagai arena akademis; dan praktis, pengetahuan penduduk setempat menjadi agenda utama dalam 
BAKTIMAS

Jurnal Pengabdian pada Masyarakat
Vol. 1, No. 4,

Desember 2019
eISSN 2685-113x

pISSN 2685-0303

pembahasan tentang pengelolaan lingkungan hidup dan sekitarnya (Altieri, 2004;Vogt et al., 2002).

Permasalahan mitra yang teridentifikasi ketika observasi dan wawancara dengan kedua mitra antara lain adalah 1) Pemahaman keberadaan unsur-unsur kebudayaan lokal dan pemetaannya supaya tidak musnah seiring dengan perkembangan zaman dan arus modernisasi; 2) Bagaimana lingkungan alam mempengaruhi kebudayaan suatu masyarakat; dan 3) Bagaimana peranan etnopedagogik dalam melestarikan keseimbangan ekosistem dan mendayagunakan kebudayaan lokal.

\section{METODE}

Pelaksanaan kegiatan program kemitraan masyarakat ini dilakukan dengan tiga tahap, pada tahap pertama merupakan tahap persiapan. Pada tahap ini tim pengusul melakukan survey ke lapangan sebagai pendahuluan untuk melihat kondisi nyata masyarakat di sekitar Cagar Alam Sancang mengenai permasalahan yang dihadapi mitra. Pada tahap ini dilakukan observasi, identifikasi serta wawancara pada pimpinan kedua mitra, yang pertama kepada kepala desa serta ketua organisasi pecinta lingkungan. Observasi dilakukan untuk mengetahui permasalahan-permasalahan yang dihadapi mitra umumnya yang berkenaan dengan tingkat pendidikan masyarakat dengan cara pandang masyarakat terhadap potensi lokal serta pengelolaan Sumber Daya Alam (SDA) Leuweung Sancang.

Tahap kedua, selanjutnya merupakan tahap pelaksanaan kegiatan program kemitraan masyarakat. Dalam tahap ini tim pengusul melakukan kegiatan penyuluhan kepada masyarakat kedua mitra mengenai bagaimana prespektif potensi lokal Sancang yang diharapkan keberadaannya tetap mampu menopang kehidupan masyarakat serta tetap lestari. Pendekatan yang digunakan dengan menanamkan pemahaman dari sudut pandang etnopedagogik. Tahap ketiga dalam kegiatan ini adalah evaluasi dengan pemberian kuis singkat mengenai pemahaman masyarakat mengenai pentingnya penatakelolaan Leuweung Sancang dan peningkatan kualitas pendidikan.

Pelaksanaan program kemitraan masyarakat ini menggunakan metode dan penyuluhan secara langsung. Masyarakat serta kader organisasi pecinta lingkungan yang umumnya merupakan siswa sekolah diberikan penyuluhan mengenai pentingnya pendidikan untuk mengubah cara pandang masyarakat terhadap potensi lokal Sancang yang menggunakan sudut pandang etnopedagogik. Waktu melakukan penyuluhan dan pelatihan bagi kedua mitra adalah 6 bulan dengan waktu pertemuan setiap mitra membutuhkan 1 kali pertemuan setiap 2 bulan, pertemuan dilakukan setiap akhir pekan.

Mitra dalam program kemitraan masyarakat yang dilaksanakan adalah masyarakat yang berasal dari dua kampung terpilih sekitar wilayah Sancang diantaranya masyarakat dari kampung Setialaksana, dan kader/anggota organisasi pecinta lingkungan yang berasal dari kampung Cirampadan. Prioritas masyarakat yang mengikuti adalah masyarakat dari berbagai kalangan yang peduli terhadap potensi lokalnya dan kader yang produktif di organisasi pecinta lingkungan yang masingmasing sebanyak 40 orang. 
Diana Hernawati, Liah Badriah, Romy Faisal Mustofa

\section{HASIL DAN PEMBAHASAN}

Hasil pengabdian masyarakat yang dilakukan berupa bentuk sosialisasi kepada masyarakat sebagai agen yang tahu secara nyata kondisi Sancang baik dari budaya, sumber daya alam dan keanekaragaman hayati. Sebuah refleksi untuk meningkatkan pemahaman etnopedagogik dalam menjaga budaya, sumber daya alam dan keanekaragaman hayati wilayah hutan Sancang. Pengabdian ini diuraikan secara terperinci berdasarkan sistematika kegiatan, meliputi:

\section{Sosialisasi Pengelolaan Potensi Lokal Sancang}

Sosialisasi ini dilakukan untuk memberikan edukasi kepada masyarakat asli Sancang, kalangan guru, siswa dan pecinta alam mengenai kelestarian alam di Hutan Sancang. Selama ini Sancang sudah mengalami degradasi perubahan cukup lama. Daya tarik manusia untuk datang ke sana dengan segala tujuan sedikit demi sedikit mulai tercium dan membawa dampak negatif untuk lingkungan di Sancang. Banyak daya tarik alam itu tidak dimaksimalkan, bahkan masyarakat mulai melakukan perambahan terhadap lahan di dalam cagar alam. Untuk itu perlu kiranya kami hadir memberikan edukasi mengenai pelestarian alam dengan metode kolaboratif.

Edukasi yang diberikan mengusung konsep etnopedagogik untuk dikembangkan dan diterapkan pada kegiatan kelompok siswa maupun pecinta alam. Etnopedagogik adalah praktik pendidikan berbasis kearifan lokal dalam berbagai ranah seperti pengobatan, seni bela diri, lingkungan hidup, pertanian, ekonomi, pemerintahan dan lain-lain. Makna lain dari etnopedagogik, adalah aktivitas mengajar lintas budaya. Etnopedagogik memandang pengetahuan atau kearifan lokal sebagai sumber inovasi dan keterampilan yang dapat diberdayakan demi kesejahteraan masyarakat. Etnopedagogik ini berkaitan erat dengan kegiatan konservasi. Konservasi di sini merupakan usaha untuk menjaga, mempertahankan dan melestarikan apa yang dimiliki untuk tetap lestari. Jadi menjaga ciri khas flora maupun fauna asli yang ada di cagar tersebut. Harapannya, dengan edukasi yang dilaksanakan secara kontinu bisa terbentuk kelompok masyarakat yang paham keberagaman budaya hayati. Gambar 1 menyajikan ketika kegiatan penyuluhan dan sosialisasi di wilayah Sancang. 
BAKTIMAS

Jurnal Pengabdian pada Masyarakat
Vol. 1, No. 4, Desember 2019
eISSN 2685-113x

pISSN 2685-0303

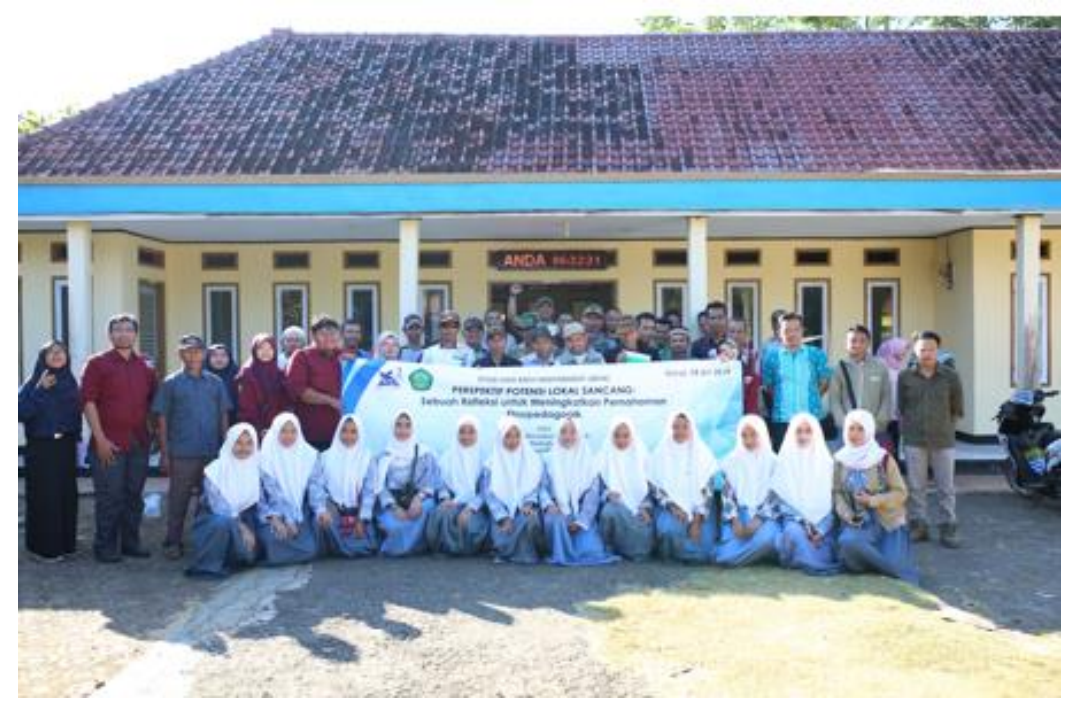

Gambar 1. Foto Bersama Setelah Selesai Kegiatan

\section{Pandangan Masyarakat Terhadap Pendidikan Kearifan Lokal}

Untuk mengetahui bagaimana pandangan masyarakat asli yang tinggal di wilayah Sancang khususnya yang berada di pinggir hutan adalah melakukan wawancara. Salah satu kuncen menjelaskan sekaitan dengan kondisi keadaan yang sebenarnya. Di wilayah Sancang sendiri terdapat banyak juru kunci yang berada di sepanjang jalan layaknya menyediakan jasa dengan adanya tanda pengenal berupa papan nama. Terdapat kurang lebih 50 juru kunci dengan berbeda keahlian untuk konsultasi dengan tamu yang datang ke juru kunci tersebut. Adat dan kebiasaan yang ada di wilayah Sancang ini begitu sangat dikagumi dan bisa dijadikan sebagai pembelajaran terkhusus bagi para kaum pendidik, sebagai salah satu contohnya dengan menjaga adat budaya dan melestarikan alam di sekitarnya atau bisa disebut juga dengan Genius Local. Salah satu kuncen perempuan menjelaskan bahwa "dirinya hanya sebagai perantara dan menanamkan budi pekerti yang baik ke setiap tamu yang datang".

Sejak Tahun 2010 kuncen perempuan ini sudah menjadi bagian dari paguyuban juru kunci di Sancang, dan merupakan sebuah anugerah dari Yang Maha Kuasa beliau bisa menjadi juru kunci, beliau menjelaskan bahwa "tugasnya untuk meluruskan dan saling mengingatkan ke sesama manusia, seperti mengajarkan dan memberikan ilmu yang baik layaknya seperti ke anak sendiri. Masing-masing orang mempunyai aturan, yang penting kita menanamkan kebaikan, kejujuran, mandat, dan amanah. Dari leluhur juga sudah mewanti-wanti untuk menitipkan dan menajaga adat dan budaya yang ada di hutan sancang". Salah satu kuncen lainnya menjelaskan bahwa kita itu adalah pramuka, dengan lambang tunas kelapa yang mempunyai arti pemimpin. Akar, tangkai, daun, buah, dan bagian-bagian lain dari kelapa pun dapat digunakan untuk kebermanfaatan manusia. Menjadi seorang pemimpin artinya harus bisa menjadi figur yang baik bagi semua bawahannya. Leluhur kita itu merupakan orang pintar, mereka pada zaman dahulu memperoleh ilmu-ilmu tersebut dengan hidup di alam. Masyarakat Sancang menjaga dan melestarikan alam disekitarnya atas perintah dan titipan dari para leluhur mereka. Namun, mereka juga berharap pemerintah dapat pula turun tangan untuk melestarikan kekayaan alam di Hutan Sancang agar kelestariannya dapat terjaga. 
Diana Hernawati, Liah Badriah, Romy Faisal Mustofa

\section{Peningkatan Kualitas Pendidikan}

Pendidikan sudah menjadi bagian fitrah manusia, karena akal yang diberikan kepada manusia dapat digunakan untuk berpikir dalam menghadapi segala tantangan lingkungan alam dan sosialnya (Shavadi, 2015). Manusia diberi potensi untuk membaca dan mempelajari lingkungannya serta memanfaatkannya demi keselamatan hidupnya. Pendidikan menuntun manusia untuk menyempurnakan rasa, karsa, cipta, dan karyanya. Pendidikan dicurahkan untuk menolong insan menyingkap dan menemui rahasia alam, memupuk bakat dan mengarah pada kecenderungannya demi kebaikan diri dan masyarakat. Manusia, pendidikan, dan lingkungan mempunyai hubungan timbal balik dan terjalin secara integral. Melalui upaya pendidikan atau transformsi budaya, diharapkan manusia dapat menyesuaikan dirinya dengan lingkungannya dan memanfaatkannya untuk kelangsungan hidupnya (Dagbaeva, 2014; Markhiva, 2018).

Di dunia ini tidak ada masyarakat manusia yang tidak mengenal lembaga maupun kegiatan pendidikan yang mempersiapkan generasi mudanya untuk memainkan peran-peran sosial dan beradaptasi dengan lingkungan secara aktif. Ini berarti bahwa pendidikan tumbuh menurut kodratnya dalam sistem sosial masyarakat modern dan tradisional. Dimana pun masyarakat itu berada dan betapapun sederhananya kehidupan mereka, pendidikan telah dikenal sebagai lembaga sosial yang penting dalam mempersiapkan generasi untuk memenuhi sistim nilai budaya yang berlaku serta mempersiapkan mereka untuk menghadapi tantangan masa depan. Salah satu ilmuwan berpendapat bahwa tidak ada masyarakat yang tidak memiliki sarana untuk mengadakan sosialisasi bagi kaum muda dan untuk meneruskan pengetahuan, keterampilan dan nilai-nilai (Dagbaeva, 2014; Valiahmetova \& Salpykova, 2015).

Selama ini ada kesenjangan yang terjadi antara sekolah dan pendidikan. Jika sekolah mengenal duduk secara resmi di dalam kelas, sedangkan pendidikan meliputi segala sesuatu yang dipelajari orang dalam seluruh pengalaman hidupnya. Pendidikan sekolah biasanya lebih menekankan kemampuan pada berpikir rasional dengan menanamkan pengetahuan yang bersifat abstrak dan umum serta kurang memperhatikan kekhususan yang diperlukan peserta didik untuk beradaptasi dengan lingkungan setempat. Akibatnya, sekolah dianggap kurang bermakna dalam mempersiapkan anggota masyarakat untuk menghadapi tantangan hidup dan memainkan peran-peran sosial meggantikan pendahulu mereka dalam lingkungan yang sama. Kecenderungannya sekolah lebih membelenggu dan memisahkan peserta didik dari kehidupan kontekstual, sebaliknya berbeda pada masyarakat yang memiliki pendidikan tradisi dengan sistem belajar asli (indegenous learning systems) dan berpegang teguh pada pengetahuan empiris yang turun temurun (Agrawal, 2002; Briggs, 2005; Jaiswal, 2019; Sillitoe, 2016).

Memaknai penjelasan di atas patut kiranya sebuah sistem pendidikan dibangun dengan kesadaran azas kebutuhan lingkungan sekitarnya. Dengan demikian nilai berguna sebuah sistem pendidikan akan searah dengan kebutuhan lingkungannya. Kualitas pendidikan akan lebih meningkat ketika terjadi interaksi yang baik antara pengetahuan formal dengan kontekstual yang didapatkan melalui masyarakat asli (indigenous peoples). Sehingga anak-anak akan menerima warisan pengetahuan empiris dan melestarikannya sebagai bakuan nilai dalam sistem belajar aslinya dan sistem sosialnya. Pengetahuan empiris yang diwariskan sebagai pendidikan tradisi tidak 
BAKTIMAS

Jurnal Pengabdian pada Masyarakat
Vol. 1, No. 4,

Desember 2019
eISSN 2685-113x

pISSN 2685-0303

beranjak dari hal-hal yang kongkrit kontekstual menjadi rasional konseptual melalui pengajaran dalam jalur sekolah dan luar sekolah (Nash, 2019; Permanent Forum on Indigenous Issues, 2006).

\section{Pendekatan Etnopedagogik}

Pedagogik bukanlah sebuah ilmu yang hanya berkonsentrasi pada aspek pembelajaran saja, tetapi aspek-aspek yang berkaitan dengan nilai-nilai yang menjadi landasan mengapa pembelajaran ini perlu dilakukan adalah menjadi landasan normatif pendidikan. Begitu pula telaah yang berkaitan dengan nilai soial, kultural, spiritual dan filosofial menjadi kajian yang lengkap terhadap pendidikan, sehingga pedagogik sebagai ilmu otonom melakukan kajian terhadap pendekatan dari keilmuan ain dengan cara fenomenologi dan hermenetutik, yang berbeda dengan kajian ilmu lain yang lebih berwarna neo-positivistis dan pragmatis (Daniels, 2016; The Higher Education Academy, 2014).

Pedagogik di Indonesia membawa warna yang khas selaras dengan nilai-nilai yang berkembang, baik aspek sosial-kulturalnya, landasan filsafat Pancasila, suasana dan iklim keberagamannya, dan tradisi keilmuan/akademik di lembaga pendidikan ataupun di masyarakat yang masih belum berkembang. Selama ini kita banyak mengabaikan sistem belajar asli yang dimiliki oleh masyarakat tradisional dan dianggap tidak cocok dengan gambaran modern. Kadang-kadang dianggap juga sebagai saingan yang tidak dikehendaki dari model-model pendidikan terbaru. Di bawah pengaruh dan orientasi asing, kita telah gagal untuk melihat secara mendalam mengenai gaya-gaya belajar asli kita, sumber-sumber belajar kita dan sistem nilai kita sebagai dasar bagaimana kita belajar. Memahami akan keberadaan sistem belajar asli dalam masyarkat tradisional, tidak berarti surut ke belakang pada dimensi nilai budaya asli yang kontradiktif dengan kehidupan modern. Sistem belajar asli dalam masyarakat tradisional memiliki kekuatan sendiri dan memainkan peranan penting dalam kehidupan sosial-ekonomi mereka. Untuk itu konsep etnopedagogik perlu untuk digali kembali dengan mengintegrasikan konsep belajar asli dengan belajar modern (Mulcahy, Cleveland, \& Aberton, 2015).

Sistem belajar asli (indigenous learning system) adalah sistem belajar yang digunakan masyarakat tradisional sebagai upaya mempertahankan dan memelihara sistem sosial masyarakatnya demi kelangsungan hidupnya. Mengambil defnisi belajar dari salah satu pakar bahwa belajar adalah suatu proses dimana pengetahuan dibangun melalui transformasi pengalaman. Sistem belajar asli dalam masyarakat tradisional secara dominan cenderung dipengaruhi oleh proses belajar melalui pengalaman kongkret (concrete experience), dimana mereka menangkap sesuatu obyek apa adanya, tergantung penglihatannya. Kemampuan mereka menangkap gejala-gejala alam tanpa makna apa adanya (aprehension), merupakan proses belajar melalui pengalaman kongkret (concrete experience) yang berkembang dalam sistem belajar asli di lingkungan keluarga dan masyarakatnya. Sistem belajar asli, secara tradisional digunakan untuk memenuhi kebutuhan-kebutuhan praktis dan untuk meneruskan warisan sosial budaya dan keterampilan serta teknologi masyarakat pedesaan dari generasi ke generasi (Briggs, 2005; Jaiswal, 2019; Sillitoe, 2016). 
Diana Hernawati, Liah Badriah, Romy Faisal Mustofa

\section{PENUTUP}

\section{Simpulan}

Etnopedagogik memandang pengetahuan atau kearifan lokal (local knowledge, local wisdom) sebagai sumber inovasi dan keterampilan yang dapat diberdayakan demi kesejahteraan masyarakat. Memahami akan keberadaan sistem belajar asli dalam masyarakat tradisional, tidak berarti surut ke belakang pada dimensi nilai budaya asli yang kontradiktif dengan kehidupan modern. Sistem belajar asli dalam masyarakat tradisional memiliki kekuatan sendiri dan memainkan peranan penting dalam kehidupan sosial-ekonomi mereka. Untuk itu konsep etnopedagogik perlu untuk digali kembali dengan mengintegrasikan konsep belajar asli dengan belajar modern. Dengan berbekal konsep etnopedagogik diharapkan masyarakat asli sebagai indigenous peoples yang menjadi agen penggiat alam terbuka untuk menjaga budaya, sumber daya alam dan keanekaragaman hayati. Hasil pengabdian ini merekomendasikan perlunya dilakukan penginventarisasian dan pendokumentasian legenda-legenda yang masih hidup maupun yang pernah hidup di kalangan masyarakat, untuk dikaji dan dianalisis nilai-nilai budayanya, khususnya yang memberikan kontribusi bagi upaya pelestarian alam. Legenda-legenda yang memuat nila-inilai positif, perlu disosialisasikan kepada generasi muda untuk menumbuhkan pengertian tentang arti pentingnya legenda bagi pelestarian lingkungan. Penyosialisasian legenda-legenda ini bisa melalui forum pendidikan formal, maupun forum-forum nonformal, seperti arena bermain dan kunjungan atau lawatan budaya.

\section{Ucapan Terima Kasih}

Kami ingin mengucapkan terima kasih kepada Lembaga Penelitian, Pengabdian kepada Masyarakat Universitas Siliwangi untuk pendanaan pengabdian kepada masyarakat, sesuai keputusan No. 234/UN58.21/PM/2019 tentang pelaksanaan program Iptek bagi Bina Masyarakat Tahun 2019.

\section{DAFTAR PUSTAKA}

Agrawal, A. (2002). Indigenous knowledge and the politics of classification. International Social Science Journal. https://doi.org/10.1111/1468-2451.00382

Altieri, M. A. (2004). Linking ecologists and traditional farmers in the search for sustainable agriculture. Frontiers in Ecology and the Environment. https://doi.org/10.1890/1540-9295(2004)002[0035:LEATFI]2.0.CO;2

Briggs, J. (2005). The use of indigenous knowledge in development: Problems and challenges. Progress in Development Studies. https://doi.org/10.1191/1464993405ps105oa

Dagbaeva, S. B. (2014). Ethnopedagogical Aspects of Modern Students Socialization. Psychological-Educational StudiesПсихолого-Педагогические Исследования. https://doi.org/10.17759/psyedu.2014060403 
BAKTIMAS

Jurnal Pengabdian pada Masyarakat
Vol. 1, No. 4,

Desember 2019
eISSN 2685-113x

pISSN 2685-0303

Daniels, H. (2016). Vygotsky and Pedagogy. Vygotsky and Pedagogy. https://doi.org/10.4324/9781315617602

Fahrutdinova, G. Z. (2016). Ethno-pedagogical factor of polycultural training. International Journal of Environmental and Science Education. https://doi.org/10.12973/ijese.2016.388a

Gow, D. (2015). The Anthropology of Development: Discourse, Agency, and Culture. Anthropological Quarterly. https://doi.org/10.2307/3317989

Guzmán, P. C., Roders, A. R. P., \& Colenbrander, B. J. F. (2017). Measuring links between cultural heritage management and sustainable urban development: An overview of global monitoring tools. Cities. https://doi.org/10.1016/j.cities.2016.09.005

Jaiswal, A. (2019). Indigenous Knowledge System and Traditional Medicinal Practitioner, (April). https://doi.org/10.23880/aeoaj-16000119

Janzen, D. H., Hallwachs, W., Jimenez, J., \& Gámez, R. (1993). The role of the parataxonomists, inventory managers and taxonomists in Costa Rica's national biodiversity inventory. In Biodiversity Prospecting.

Markhiva, M. V. (2018). Conclusions from the Research of Scientific Ap-proach to Ethnopedagogics Development in Recent Times. Dagestan State Pedagogical University. Journal. Psychological and Pedagogical Sciences. https://doi.org/10.31161/1995-0659-2018-12-2-66-71

Mulcahy, D., Cleveland, B., \& Aberton, H. (2015). Learning spaces and pedagogic change: envisioned, enacted and experienced. Pedagogy, Culture and Society. https://doi.org/10.1080/14681366.2015.1055128

Nash, A. (2019). Indigenous peoples. In The Routledge Handbook to the History and Society of the Americas. https://doi.org/10.4324/9781351138703

Permanent Forum on Indigenous Issues. (2006). Who are indigenous peoples? Indigenous Peoples, Indigenous Voices.

Shavadi, A. (2015). New information technologies in ethnopedagogical process. In 9th International Conference on Application of Information and Communication Technologies, $\quad$ AICT $2015 \quad$ - $\quad$ Proceedings. https://doi.org/10.1109/ICAICT.2015.7338630

Sheil, D. (2001). Conservation and biodiversity monitoring in the tropics: Realities, priorities, and distractions. Conservation Biology. https://doi.org/10.1046/j.1523$\underline{1739.2001 .0150041179 . x}$ 
Diana Hernawati, Liah Badriah, Romy Faisal Mustofa

Sheil, D., \& Lawrence, A. (2004). Tropical biologists, local people and conservation: New opportunities for collaboration. Trends in Ecology and Evolution. https://doi.org/10.1016/j.tree.2004.09.019

Sillitoe, P. (2016). Indigenous knowledge. In The Ashgate Research Companion to Anthropology. https://doi.org/10.4324/9781315612744

The Higher Education Academy. (2014). Pedagogic theory. The Higher Education Academy. https://doi.org/10.1111/j.1944-9720.1990.tb00424.X

Valiahmetova, A. N., \& Salpykova, I. M. (2015). The role of ethnopedagogics in the development of empathic culture in students. Review of European Studies. https://doi.org/10.5539/res.v7n6p289

Vogt, K. A., Beard, K. H., Hammann, S., Palmiotto, J. O., Vogt, D. J., Scatena, F. N., \& Hecht, B. P. (2002). Indigenous Knowledge Informing Management of Tropical Forests: The Link between Rhythms in Plant Secondary Chemistry and Lunar Cycles. AMBIO: A Journal of the Human Environment. https://doi.org/10.1579/0044-7447-31.6.485 